\title{
PENGARUH KESIAPAN GURU TERHADAP PEMANFAATAN E-LEARNING
}

\author{
Riut Iptian \\ Pendidikan Akuntansi Fakultas Ekonomi \\ Universitas Negeri Yogyakarta \\ riutiptian23@gmail.com
}

\begin{abstract}
Learning based on e-lerning system is a form of solution needed in the era of globalization in education today. For this reason, it is important for teachers to have readiness in using e-learning. The purpose of this study is to determine the effect of teacher readiness towards the use of e-learning. The method used is simple regression analysis with SHS economic teacher in Bantul Regency as respondents. The results of the study indicate that there is a: (1) Significant positive influence between the IT skills towards the use of e-learning. (2) Significant positive influence between perception of ease towards the use of e-learning. (3) Significant positive effect between perception of usefulness towards the use of e-learning. (4) Significant positive influence between the IT skills, perceived ease of use, and perceived usefulness simultanly towards the use of e-learning. It can be concluded that teacher readiness is one of the factors that can influence the success of e-learning. For this reason, teachers need to improve their abilities in terms of mastering information technology so that digital-based education can be applied in learning activities well.
\end{abstract}

Key words: IT Skills, Perceived Ease of Use, Perceived Usefulness, E-learning

\begin{abstract}
Abstrak: Pembelajaran berbasis sistem e-learning merupakan bentuk solusi yang dibutuhkan di era globalisasi dalam dunia pendidikan saat ini. Untuk itu, penting bagi guru untuk memiliki kesiapan dalam pemanfaatan e-learning. Tujuan dalam penelitian ini yaitu untuk mengetahui pengaruh kesiapan guru terhadap pemanfaatan e-learning. Metode yang digunakan yaitu analisis regresi sederhana dengan responden guru ekonomi SMA se Kabupaten Bantul. Hasil penelitian menunjukkan bahwa: (1) Terdapat pengaruh postif signifikan antara kemampuan $\mathrm{TI}$ terhadap pemanfaatan e-learning. (2) Terdapat pengaruh positif signifikan antara persepsi kemudahan terhadap pemanfaatan $e$ learning. (3) Terdapat pengaruh positif signifikan antara persepsi kemanfaatan terhadap pemanfataan e-learning. (4) Terdapat pengaruh positif signifikan antara kemampuan TI, persepsi kemudahan, dan persepsi kesiapan guru secara simultan terhadap pemanfaatan e-learning. Dapat disimpulkan bahwa kesiapan guru merupakan salah satu faktor yang dapat mempengarui keberhasilan pemanfaatan e-learning. Untuk itu, guru perlu meningkatkan kemampuannya dalam hal penguasaan teknologi informasi agar pendidikan berbasis digital dapat diterapkan dalam kegiatan pembelajaran dengan baik.
\end{abstract}

Kata kunci: Kemampuan TI, Persepsi Kemudahan, Persepsi Kemanfaatan, E-learning

Sistem pembelajaran e-learning membawa pengaruh yang signifikan terhadap dunia pendidikan. Pendidikan yang bersifat konvensional telah digeser menuju pendidikan era digital oleh perkembangan teknologi. Sistem pembelajaran yang berbasis e-learning memberikan berbagai manfaat yang dapat diterima oleh guru, antara lain yaitu memberikan kesempatan kepada guru untuk melakukan pembelajaran secara jarak jauh tanpa terpaku pada pembelajaran di dalam kelas, komunikasi tanpa terhalang jarak dan waktu dengan sistem online, fleksibilitas cara mengajar, efisiensi biaya, pembelajaran yang lebih terarah dan terintegrasi, serta dapat dimanfaatkan sebagai ruang penyimpanan berbagai informasi, materi pembelajaran, soal, maupun tugas sehingga dapat disimpan 
dalam bentuk database dan dimanfaatkan sewaktu-waktu (Arkorful \& Abaidoo, 2014) (Jethro, Grace, \& Thomas, 2012) (Guragain, 2016).

Berbagai manfaat di atas tentunya akan membawa sebuah reformasi besar dalam dunia pendidikan apabila mampu dimanfaatkan secara maksimal oleh para tenaga pendidik. Tidak hanya guru, siswa juga akan mendapatkan berbagai manfaat kemudahan, kemampuan siswa terhadap penguasaan teknologi informasi akan terasah dengan mengajarkan dan membiasakan mereka menggunakan pembelajaran berbasis e-learning sedini mungkin. Untuk itu, sistem elearning merupakan salah satu bentuk solusi yang sangat dibutuhkan di era globalisasi dunia pendidikan saat ini (Yulianto, 2011).

Terlebih lagi bahwa dalam kurikulum 2013 yang diterapkan pemerintah saat ini, pemanfaatan e-learning merupakan suatu keharusan untuk semua mata pelajaran (Waryanto \& Insani, 2010). Peraturan tersebut merupakan bentuk respon pemerintah terhadap adanya perkembangan digital yang sangat pesat, dengan harapan bahwa baik guru maupun murid dapat memiliki keterampilan yang lebih dalam pemanfaatan teknologi informasi.

Berdasarkan hasil penelitian yang dilakukan (Waryanto \& Insani, 2010), menunjukkan bahwa guru-guru di Kota Yogyakarta memiliki tingkat kesiapan yang secara umum ditakegorikan cukup siap untuk mengimplementasikan e-learning. Namun dalam pengamatan secara umum,e-learning belum diaplikasikan secara merata oleh semua guru maupun institusi. Realita menunjukkan bahwa masih banyak pengajar yang tidak bisa memaksimalkan model pembelajaran berbasis e-learning akibat kurangnya kemahiran dan pengetahuan dalam menguasai alat pembelajaran (Hendrastomo, 2008). Untuk itu, tujuan penelitian dalam artikel ini yaitu untuk mengetahui pengaruh kesiapan guru terhadap pemanfaatan e-learning.

E-learning oleh (Horton \& Horton, 2010) diartikan sebagai penggunaan informasi dan tekonologi komputer untuk menciptakan pengalaman belajar. E-learning merupakan kegiatan belajar mengajar yang memungkinkan tersampaikannya materi pembelajaran pada siswa dengan menggunakan media intranet, internet, maupaun media jaringan komputer lain.
Sedangkan definisi secara lebih luas disampaikan oleh (LearnFrame.com, 2001) yang menyatakan bahwa e-learning merupakan suatu sistem pendidikan yang memanfaatkan aplikasi elektronik untuk mendukung kegiatan belajar mengajar dengan media internet, komputer, maupun jaringan komputer. Dengan demikian, dapat disimpulkan bahwa e-learning merupakan suatu sistem pendidikan yang dalam prosesnya memanfaatkan media internet maupun teknologi informasi lainnya untuk mendukung kegiatan belajar mengajar.

Fungsi e-learning dalam pendidikan sendiri dapat dikategorikan menjadi tiga. Adapun ketiga fungsi tersebut menurut (Siahaan, 2002) yaitu: (1) Sebagai Suplemen (Tambahan), yaitu apabila siswa memiliki kebebasan untuk memilih apakah akan memanfaatkan materi pembelajaran secara elektronik atau tidak. Tidak ada kewajiban bagi siswa untuk mengakses materi yang ada pada e-learning (2) Sebagai Komplemen (Pelengkap), yaitu dimana materi pembelajaran elektronik ditujukan untuk melengkapi pembelajaran siswa di dalam kelas. Materi dapat berfungsi sebagai bahan pengayaan maupun remidial bagi siswa. (3) Sebagai Substitusi (Pengganti), yaitu apabila e-learning diterapkan secara penuh sehingga tidak terikat pada pembelajaran di dalam kelas, materi secara keseluruhan disampaikan melalui media elektronik.

Adapun keberhasilan dalam penerapan e-learning akan dipengaruhi oleh kesiapan penerapan e-learning itu sendiri. (Chapnick, 2000) mengelompokkan kesiapan e-learning ke dalam delapan kategori kesiapan, yaitu:

a. Psychological readiness. Faktor ini mempertimbangkan sudut pandang individu terhadap pegaruh inisiatif e-learning. Faktor ini merupakan faktor terpenting yang harus diperhatikan dalam implementasi.

b. Sociological readiness. Sociological readiness ini mempertimbangkan faktor interpersonal lingkungan dimana program akan diimplementasikan.

c. Environmental readiness. Faktor ini mempertimbangkan operasi dan kekuatan besar pada stakeholder, di dalam maupun di luar organisasi.

d. Human resource readiness. Faktor ini mempertimbangkan rancangan sistem dukungan sumber daya manusia dan ketersediannya. 
e. Financial readiness. Faktor ini mempertimbangkan proses alokasi dan besarnya anggaran.

f. Technological skill (aptitude) readiness. Faktor ini mempertimbangkan kompetensi teknis yang dapat diukur dan diamati.

g. Equipment readiness. Faktor ini mempertimbangkan kepemilikan peralaran yang sesuai.

h. Content readiness. Faktor ini mempertimbangkan sasaran pembelajaran dan konten pembelajaran.

Sedangkan (Swatman, 2006) mengelompokkan komponen kesiapan elearning ke dalam enam komponen, yaitu: kesiapan, yaitu:

a. Students preparedness. Kesiapan dari siswa untuk menerapkan e-learning

b. Teacher preparedness. Kesiapan dari guru untuk menggunakan fasilitas e-learning dalam keiatan belajar mengajar.

c. IT Infrastructure. Kesiapan TI yang meliputi software, hardware, dan network.

d. Management Support. Dukungan institusi terkait kebijakan, regulasi, dan keuangan pada penerapan e-learning.

e. School Culture. Bagaimana budaya yang ada dalam institusi terkait hubungan anatara siswa dengan gurunya, dan kebijakan dalam mengatur reward dan punnishment.

f. Preference to Meet Face to Face. Bagaimana preferensi siswa dan dosen untuk melaksanakan pembelajaran secara online atau pembelajaran secara tatapmuka.

Berdasarkan pendapat dari Chapnick dan Swatman di atas, keduanya sepakat bahwa salah satu satu faktor yang mempengaruhi kesiapan pemanfaatan e-learning adalah kemampuan teknologi informasi dari pengajar. Chapnick mengungkapkan sebagai Technological skill (aptitude) readiness sedangkan Swatman mengelompokkannya sebagai Teacher Preparedness, dimana keduanya mengatakan bahwa kemampuan seoarang guru dalam penguasaan teknologi informasi merupakan faktor yang penting bagi berjaannya pembelajaran berbasis e-learning.

Menurut (O'Brien \& James, 2006) teknologi adalah suatu jaringan komputer yang terdiri atas berbagai komponen pemrosesan informasi yang menggunakan berbagai jenis hardware, software, manajemen data, dan teknologi jaringan informasi. Sedangkan menurut (Rahmawati, 2008) teknologi informasi adalah segala cara atau alat yang yang terintegrasi yang digunakan untuk menjaring data, mengolah dan mengirimkan atau menyajikan secara elektronik menjadi informasi dalam berbagai format yang bermanfaat bagi pemakainya. Dengan demikian, TI dapat mencakup berbagai alat maupun aplikasi software yang dapat menyimpan, memproses dan menyebarkan informasi seperti komputer, telepon genggam, faksimili, termasuk aplikasi software yang ada di dalam komputer seperti e-mail, situs web, dan lain-lain.

Kemudian apabila dilihat dari teori TAM (Technology Acceptance Model) yang dikembangkan oleh Davis F.D. pada tahun 1989, menjelaskan bahwa perilaku individu dalam menggunakan teknologi informasi dipengaruhi oleh dua konstruksi, yaitu persepsi individu terhadap kemudahan penggunaan teknologi tersebut (perceived ease of use) dan persepsi individu terhadap kemanfaatan yang akan diterima dari teknologi tersebut (perceived usefulness). Model ini secara lebih jelas menggambarkan bahwa penerimaan penggunaan TI dipengaruhi oleh kemanfaatan dan kemudahan penggunaan (Yulianto, 2011).

Persepsi tentang kemudahan (perceived ease of use) penggunaan sebuah teknologi didefinisikan sebagai suatu ukuran dimana seseorang percaya bahwa komputer dapat dengan mudah dipahami dan digunakan Davis. F. D, 1989 dalam (Yulianto, 2011). Sedangkan Persepsi terhadap kemanfaatan didefinisikan sebagai suatu ukuran dimana penggunaan suatu teknologi dipercaya akan mendatangkan manfaat bagi orang yang menggunakannya (Davis. F. D, 1989 dalam (Yulianto, 2011).

Berdasarkan berbagai paparan mengenai faktor yang mempengaruhi kesiapan dalam pemanfaatan e-learning di atas, untuk variabel yang dipakai dalam penelitian ini yaitu Kemampuan TI, Persepsi Kemudahan, dan Persepsi Kemanfaatan. Dalam penelitian ini guru dijadikan sebagai subjek penelitian dikarenakan guru merupakan ujung tombak di dalam pembelajaran. Pengajar atau pendidik lah yang akan menjadi aktor utama penggerak pembelajaran berbasis e-learning (Hendrastomo, 2008). 
Dengan demikian, peneliti mengajukan empat hipotesis, yaitu: (1) Terdapat pengaruh positif signifikan antara kemampuan TI terhadap pemanfaatan e-learning. (2) Terdapat pengaruh positif signifikan antara persepsi kemudahan terhadap pemanfataan e-learning. (3) Terdapat pengaruh positif signifikan antara persepsi kemanfaatan terhadap pemanfaatan e-learning. (4) Terdapat pengaruh positif signifikan antara kemampuan TI, persepsi kemudahan, dan persepsi kesiapan secara simultan terhadap pemanfaatan e-learning.

\section{METODE}

Penelitian ini merupakan penelitian expost facto dengan pendekatan kuantitatif. Penelitian ini terdiri dari tiga variabel bebas, yaitu Kemampuan TI (X1), Persepsi Kemudahan (X2), Persepsi Kemanfaatan (X3), dan Pemanfaatan E-learning (Y). Berdasarkan variabel-variabel tersebut maka dapat disusun paradigma penelitian sebagai berikut:

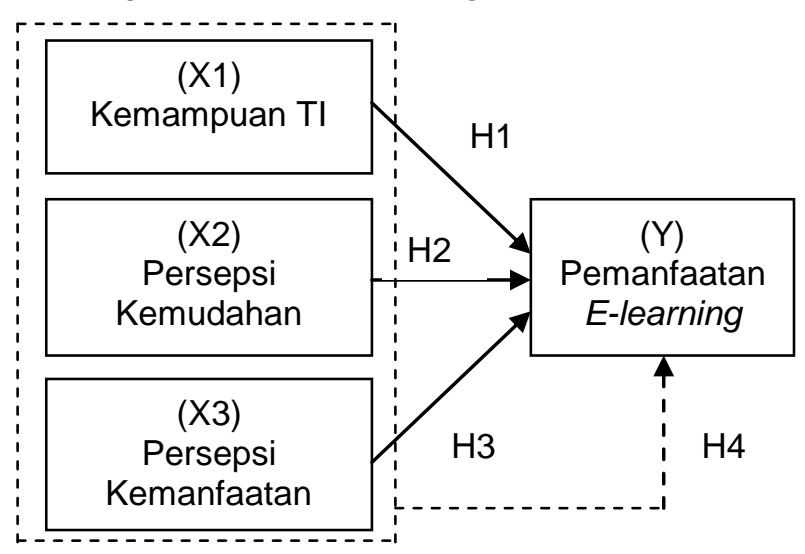

Gambar 1 Paradigma Penelitian

Responden dalam penelitian ini merupakan guru ekonomi yang tergabung dalam MGMP Ekonomi Kabupaten Bantul yang berjumlah 68 guru. Pengumpulan data dalam penelitian ini menggunakan kuisioner dengan empat pilihan jawaban (skala likert) yaitu (SS), setuju (S), tidak setuju (ST), dan sangat tidak setuju (STS). Teknik analisis data yang digunakan yaitu analisis regresi sederhanadan berganda. Adapun variabel dan indikator dalam penelitian ini yaitu:

Tabel 1. Variabel dan Indikator

\begin{tabular}{|c|c|}
\hline Variabel & Indikator \\
\hline \multirow[t]{2}{*}{ Kemampuan TI } & $\begin{array}{l}\text { - Mengoperasikan } \\
\text { alat (hardware) }\end{array}$ \\
\hline & $\begin{array}{l}\text { - Mengaplikasikan } \\
\text { software }\end{array}$ \\
\hline
\end{tabular}

\begin{tabular}{|c|c|c|}
\hline & - & $\begin{array}{l}\text { Menyimpan, } \\
\text { memproses, } \\
\text { menyebarkan } \\
\text { informasi melalui } \\
\text { komputer, telepon } \\
\text { genggam, e-mail, } \\
\text { website }\end{array}$ \\
\hline \multirow[t]{4}{*}{$\begin{array}{l}\text { Persepsi } \\
\text { Kemudahan }\end{array}$} & - & $\begin{array}{l}\text { Komputer sangat } \\
\text { mudah dipelajari }\end{array}$ \\
\hline & - & $\begin{array}{l}\text { Komputer sangat } \\
\text { mudahuntuk } \\
\text { dioperasikan }\end{array}$ \\
\hline & - & $\begin{array}{l}\text { Komputer sangat } \\
\text { mudah untuk } \\
\text { meningkatkan } \\
\text { keterampilan } \\
\text { pengguna }\end{array}$ \\
\hline & - & $\begin{array}{l}\text { Komputer } \\
\text { mengerjakan } \\
\text { dengan mudah apa } \\
\text { yang diinginkan oleh } \\
\text { pengguna }\end{array}$ \\
\hline \multirow[t]{3}{*}{$\begin{array}{l}\text { Persepsi } \\
\text { Kemanfaatan }\end{array}$} & - & $\begin{array}{l}\text { Komputer } \\
\text { mendatangkan } \\
\text { manfaat bagi } \\
\text { pengguna }\end{array}$ \\
\hline & - & $\begin{array}{l}\text { Komputer dapat } \\
\text { meningkatkan } \\
\text { kinerja }\end{array}$ \\
\hline & & $\begin{array}{l}\text { Komputer dapat } \\
\text { meningkatkan } \\
\text { prestasi kerja }\end{array}$ \\
\hline
\end{tabular}

\section{HASIL DAN PEMBAHASAN}

Tabel 2. Rangkuman Hasil Uji H1

\begin{tabular}{cccc}
\hline Variabel & \multicolumn{2}{c}{ Harga $r$ dan $r^{2}$} & Harga $t$ \\
\cline { 2 - 3 } & $r_{\text {hitung }}$ & $r^{2}$ & hitung \\
\hline$X_{1}-Y$ & 0,489 & 0,239 & 5,911 \\
\hline
\end{tabular}

Sumber: Data Primer

Dari tabel di atas diperoleh hasil pengujian hipotesis dengan regresi sederhana satu prediktor $\left(\mathrm{rx}_{1} \mathrm{y}\right)$ bernilai positif sebesar 0,489 , artinya Kemampuan TI terhadap Pemanfaatan E-learning memiliki pengaruh positif. Untuk mengetahui signifikansi pengaruh digunakan uji t. Dari uji t diperoleh $t$ hitung sebesar 5,911 > $\mathrm{t}$ tabel pada taraf signifikansi $5 \%$ sebesar 1,981 maka t hitung > $t_{\text {tabel. }}$. Hal ini menunjukkan bahwa terdapat 
pengaruh signifikan Kemampuan TI terhadap Pemanfaatan E-learning.

Hasil di atas memperkuat pendapat yang dikemukakan oleh (Chapnick, 2000) dan (Swatman, 2006), di mana keduanya mengungkapkan bahwa Kemampuan TI dapat mempengaruhi kesiapan seorang guru dalam mengaplikasikan pembelajaran berbasis $e$ learning. Seorang guru yang dapat mengoperasikan hardware maupun software secara terampil, mampu menyimpan, memproses, mengolah, dan menyebarkan informasi melalui media berbasis TI tentunya akan memiliki kecenderungan lebih untuk memanfaatkan e-learning. Adanya kesiapan dalam bentuk keterampilan penguasaan alat akan membawa kepercayaan diri lebih kepada guru untuk memanfaatkan e-learning. Pada hipotesis pertama ini dapat disimpulkan bahwa kemampuan guru dalam menguasi teknologi informasi berpengaruh secara positif dan signifikan terhadap pemanfaatan e-learning.

Tabel 3. Rangkuman Hasil Uji H2

\begin{tabular}{cccc}
\hline Variabel & \multicolumn{2}{c}{ Harga $r$ dan $r^{2}$} & Harga $t$ \\
\cline { 2 - 3 } & $r_{\text {hitung }}$ & $r^{2}$ & hitung \\
\hline $\mathrm{X}_{2}-\mathrm{Y}$ & 0,374 & 0,140 & 4,224 \\
\hline
\end{tabular}

Sumber: Data Primer

Dari tabel di atas diperoleh hasil pengujian hipotesis dengan regresi sederhana satu prediktor $\left(\mathrm{rx}_{2} \mathrm{y}\right)$ bernilai positif sebesar 0,374, artinya Persepsi Kemudahan terhadap Pemanfaatan E-learning memiliki pengaruh positif. Untuk mengetahui signifikansi pengaruh digunakan uji t. Dari uji t diperoleh $t_{\text {hitung }}$ sebesar 4,224 >t tabel pada taraf signifikansi $5 \%$ sebesar 1,981 maka t hitung $>t$ tabel. Hal ini menunjukkan bahwa terdapat pengaruh signifikan Persepsi Kemudahan terhadap Pemanfaatan E-learning.

Hasil di atas memperkuat adanya teori TAM (Technology Acceptance Model) yang dikemukakan oleh Davis F.D.(1989). Di mana persepsi kemudahan guru terhadap teknologi informasi dapat mempengaruhi kesiapan guru tersebut untuk mengaplikasikannya. Adanya persepsi bahwa mengaplikasikan teknologi informasi mudah, akan membawa seseorang untuk mau dan berminat untuk mempelajarinya. Pada hipotesis kedua ini dapat disimpulkan bahwa persepsi kemudahan berpengaruh secara positif dan signifikan terhadap pemanfaatan e-learning.
Tabel 4. Rangkuman Hasil Uji H3

\begin{tabular}{cccc}
\hline Variabel & \multicolumn{2}{c}{ Harga $r$ dan $r^{2}$} & Harga $t$ \\
\cline { 2 - 3 } & $r_{\text {hitung }}$ & $r^{2}$ & hitung \\
\hline$X_{3}-Y$ & 0,394 & 0,155 & 4,510 \\
\hline
\end{tabular}

Sumber: Data Primer

Dari tabel di atas diperoleh hasil pengujian hipotesis dengan regresi sederhana satu prediktor $\left(\mathrm{rx}_{3} \mathrm{y}\right)$ bernilai positif sebesar 0,394, artinya Persepsi Kemanfaatan terhadap Pemanfaatan E-learning memiliki pengaruh positif. Untuk mengetahui signifikansi pengaruh digunakan uji t. Dari uji t diperoleh t hitung sebesar 4,510 $>t_{\text {tabel }}$ pada taraf signifikansi $5 \%$ sebesar 1,981 maka t hitung > $t_{\text {tabel. }}$. Hal ini menunjukkan bahwa terdapat pengaruh signifikan Persepsi Kemanfaatan terhadap Pemanfaatan E-learning.

Hasil di atas juga memperkuat teori TAM (Technology Acceptance Model) dari Davis F.D.(1989). Di mana persepsi kemanfaatan dari seseorang guru dapat mempengaruhi kesiapan guru tersebut untuk mengaplikasikan e-learning dalam kegiatan belajar mengajar. Kesadaran guru akan berbagai manfaat yang akan diterima dengan memanfaatkan teknologi informasi tentunya akan membawa guru untuk lebih berminat dalam memanfaatkan e-learning dalam pembelajaran. Pada hipotesis ketiga ini dapat disimpulkan bahwa persepsi kemanfaatan berpengaruh secara positif dan signifikan terhadap pemanfaatan e-learning

Tabel 5. Rangkuman Hasil Uji H4

\begin{tabular}{|c|c|c|c|c|}
\hline \multicolumn{2}{|c|}{ Variabel } & \multicolumn{2}{|c|}{ Harga $\mathrm{R}$ dan $\mathrm{R}^{2}$} & Harga \\
\cline { 4 - 5 } \multicolumn{2}{|c|}{} & $\mathrm{R}_{\mathrm{y}(1,2,3)}$ & $\mathrm{R}^{2} \mathrm{y}(1,2,3)$ & $\mathrm{F}_{\text {hitung }}$ \\
\hline $\mathrm{X}_{1}$ & \multirow{2}{*}{$\mathrm{Y}$} & 0,509 & 0,259 & 12,712 \\
\hline $\mathrm{X}_{2}$ & & & \\
\hline $\mathrm{X}_{3}$ & & & & \\
\hline
\end{tabular}

Sumber: Data Primer

Dari tabel di atas diperoleh hasil pengujian hipotesis dengan regresi ganda tiga prediktor $\mathrm{R}_{\mathrm{y}}(1,2,3)$ bernilai positif sebesar 0,509; artinya Kemampuan TI, Persepsi Kemudahan, dan Persepsi Kemanfaatan secara bersamasama memiliki pengaruh positif terhadap Pemanfaatan E-learning. Dari uji $\mathrm{F}$ diperoleh $\mathrm{F}$ hitung sebesar 12,712 $>F_{\text {tabel }}$ pada taraf signifikansi $5 \%$ sebesar 2,455 maka $F>F$ tabel. $\mathrm{Hal}$ ini menunjukkan bahwa terdapat pengaruh signifikan Kemampuan TI, Persepsi Kemudahan, dan Persepsi Kemanfaatan 
secara bersama-sama terhadap Pemanfaatan E-learning.

Hasil ini memperkuat teori yang ada mengenai faktor-faktor yang mempengaruhi kesiapan pemanfaatan e-learning. Pendapat yang dikemukakan oleh (Chapnick, 2000), (Swatman, 2006), dan Davis F.D. (1989) diperkuat oleh adanya hasil penelitian ini. Pada hipotesis keempat ini dapat disimpulkan bahwa Kemampuan TI, Persepsi Kemudahan, dan Persepsi Kemanfaatan secara bersama-sama memiliki pengaruh positif signifikan terhadap Pemanfaatan E-learning.

\section{KESIMPULAN}

Berdasarkan hasil pengolahan data dapat disimpulkan bahwa: (1) Terdapat pengaruh postif signifikan antara kemampuan TI terhadap pemanfaatan e-learning. (2) Terdapat pengaruh positif signifikan antara persepsi kemudahan terhadap pemanfaatan e-learning. (3) Terdapat pengaruh positif signifikan antara persepsi kemanfaatan terhadap pemanfataan e-learning. (4) Terdapat pengaruh positif signifikan antara kemampuan TI, persepsi kemudahan, dan persepsi kesiapan guru secara simultan terhadap pemanfaatan e-learning.

\section{SARAN}

Untuk menyempurnakan hasil penelitian ini diperlukan adanya pengembangan pada faktorfaktor lainnya sehingga dapat memberikan hasil yang lebih akurat. Hasil penelitian ini dapat dijadikan sebagai bahan pertimbangan bagi pihak-pihak yang berkepentingan seperti sekolah, pemerintah, maupun institusi lain. Program pelatihan untuk guru dapat direncanakan dalam rangka meningkatkan skill dan kemampuan guru dalam memanfaatkan teknologi informasi, sehingga untuk kedepannya pemanfaatan e-learning dapat dilaksanakan secara lebih luas dan merata.

\section{DAFTAR RUJUKAN}

Arkorful, V., \& Abaidoo, N. (2014). The Role of E-learning, The Advantages and Disadvantages of its Adoption in Higher Education. International Journal of Education Research, 2(12).

Chapnick, S. (2000). Are You Ready for ELearning? Learning Circuits.
Guragain, N. (2016). E-learning Benefits and Applications. Helsinki Metropolia University.

Hendrastomo, G. (2008). Dilema dan Tantangan Pembelajaran E-learning. Majalah IImiah Pembelajaran, 4(1).

Horton, W., \& Horton, K. (2010). E-learning Tools and Technologies: A Consumer's Guide for Trainers, Teachers, Educators, and Instructional Designers (pp. 12-24). pp. 12-24. Wiley Publishing.

Jethro, O. O., Grace, A. M., \& Thomas, A. K. (2012). E-learning and Its Effects on Teaching and Learning in a Global Age. International Journal of Academic Research in Business and Social Sciences, 2(1).

LearnFrame.com. (2001). Glossary of ELearning Term.

O'Brien, \& James, A. (2006). Pengantar Teknologi Sistem Informasi Perspektif Bisnis dan Manajerial. Jakarta: Salemba Empat.

Rahmawati, D. (2008). Analisis Faktor Faktor yang Berpengaruh Terhadap Pemanfaatan Teknologi Informasi. Jurnal Ekonomi Dan Pendidikan, 5(1).

Siahaan, S. (2002). Studi Penjajagan Tentang Kemungkinan Pemanfaatan Internet Untuk Pembelajaran di SLTA di Wilayah Jakarta dan Sekitarnya. Jurnal Pendidikan Dan Kebudayaan, 8(39).

Swatman, P. M. . (2006). E-learning Readiness of Hongkong Teachers. Proceedings of the Fifth IEEE International Conference on Advanced Learning Technologies.

Waryanto, N. H., \& Insani, N. (2010). Tingkat Kesiapan (Readiness) Implementasi Elearning di Sekolah Menengah Atas Kota Yogyakarta. Universitas Negeri Yogyakarta.

Yulianto, S. E. (2011). Pengaruh Persepsi Kemudahan dan Persepsi Kemanfaatan Terhadap Pemanfaatan E-learning Dengan Model TAM di SMK Muhammadiyah 3 Yogyakarta. JBTI, 2(1). 